\title{
Religiosity and prevalence of suicide, psychiatric disorders and psychotic symptoms in the French general population
}

\author{
Running title: Religiosity and psychiatric disorders
}

Maria Alice Brito ${ }^{1,2}$, Ali Amad ${ }^{3,4,5}$, Benjamin Rolland ${ }^{6}$, Pierre A. Geoffroy ${ }^{2,7}$, Hugo Peyre ${ }^{2,8}$, Jean-Luc Roelandt $^{9}$, Imane Benradia ${ }^{9}$, Pierre Thomas ${ }^{3,4}$, Guillaume Vaiva ${ }^{3,10}$, Franck Schürhoff ${ }^{1,11,12,13}$, Baptiste Pignon $^{1,11,12,13, *}$.

\footnotetext{
${ }^{1}$ AP-HP, DMU IMPACT, Département Médico-Universitaires de psychiatrie et d'addictologie des Hôpitaux universitaires HenriMondor, Créteil, 94000, France.

${ }^{2}$ Paris University, Paris, France.

${ }^{3}$ Lille Neurosciences and Cognition, Lille University Hospital, University of Lille, and National Institute of Health and Medical Research, U1172, Lille, France.

${ }^{4}$ Fédération Régionale de Recherche en Santé Mentale (F2RSM) Hauts-de-France, rue André Verhaeghe, Lille F-59000, France.

${ }^{5}$ King's College London, Institute of Psychiatry, Psychology and Neuroscience, 16 De Crespigny Park, Camberwell, London, UK.

${ }^{6}$ Service Universitaire d'Addictologie de Lyon (SUAL), CH Le Vinatier, Bron France ; CRNL, Inserm U1028 - CNRS UMR5292, UCBL, Université de Lyon, Lyon, France.

${ }^{7}$ Department of Psychiatry and Addictive Medicine, Assistance Publique-Hôpitaux de Paris (AP-HP), University Hospital Bichat, 46 rue Henri Huchard, 75018 Paris, France ; Université de Paris, NeuroDiderot, Inserm, F-75019 Paris, France

${ }^{7}$ Psychiatry and Addiction Medicine Department, CHU Lille, Lille, France.

${ }^{8}$ Assistance Publique-Hôpitaux de Paris, Robert Debré Hospital, Child and Adolescent Psychiatry Department, Paris, France.

${ }^{9}$ EPSM Lille Métropole ; Centre Collaborateur de l'Organisation Mondiale de la Santé pour la Recherche et la Formation en Santé Mentale ; Équipe Eceve Inserm UMR 1123, 211 rue Roger Salengro, F-59 260 Hellemmes, France.

${ }^{10}$ Centre National de Ressources et Résilience pour les psychotraumatismes (Cn2r), Lille Paris, France ;

${ }^{11}$ Inserm, U955, Laboratoire Neuro-Psychiatrie translationnelle, Institut Mondor de Recherche Biomédicale, Créteil, 94000, France ;

${ }^{12}$ Fondation FondaMental, Créteil, 94000, France.

${ }^{13}$ UPEC, Université Paris Est Créteil, Faculté de médecine, Créteil, 94000, France.
}

\section{*Corresponding author:}

Dr. Baptiste Pignon

Hôpital Albert Chenevier, Groupe hospitaliers Henri-Mondor, CHU de Créteil, Assistance Publique-

Hôpitaux de Paris (AP-HP), 40 rue de Mesly, 94 000, Créteil, France

baptistepignon@yahoo.fr

缁 : + 33149813131 ; Fax : +33149813059

ORCID: 0000-0003-0526-3136

Word count: 3,731 


\section{ABSTRACT}

\section{Objective}

We aimed to examine the association between religious beliefs and observance and the prevalence of psychiatric disorders, psychotic symptoms and history of suicide attempts in the French general population.

\section{Methods}

The cross-sectional survey interviewed 38,694 subjects between 1999 and 2003, using the MINI. Current religious beliefs and observance were identified by means of two questions: "are you a believer?" and "are you religiously observant?'. We studied the association between religiosity and psychiatric outcomes using a multivariable logistic regression model adjusted for sociodemographic characteristics, including migrant status.

\section{Results}

Religious beliefs were positively associated with psychotic symptoms and disorders ( $\mathrm{OR}=1.37,95 \% \mathrm{CI}$ [1.30-1.45] and $\mathrm{OR}=1.38,95 \% \mathrm{CI}$ [1.20-1.58]), unipolar depressive disorder (OR=1.15, 95\% CI [1.06-1.23]) and generalized anxiety disorder ( $\mathrm{OR}=1.13,95 \% \mathrm{CI}$ [1.06-1.21]), but negatively associated with bipolar disorder $(\mathrm{OR}=0.83,95 \%$ CI [0.69-0.98]), alcohol use disorders (OR=0.69, 95\% CI [0.62-0.77]), substance use disorders $(\mathrm{OR}=0.60,95 \% \mathrm{CI}[0.52-0.69])$ and suicide attempts (OR=0.90, 95\% CI [0.82-0.99]). Religious observance was positively associated with psychotic symptoms and disorders $(\mathrm{OR}=1.38,95 \% \mathrm{CI}$ [1.20-1.58] and $\mathrm{OR}=1.25$, 95\% CI [1.07-1.45]), but negatively associated with social anxiety disorder $(\mathrm{OR}=0.87,95 \%$ CI [0.76-0.99]), alcohol use disorders (OR=0.60, 95\% CI [0.51-0.70]), substance use disorders $(\mathrm{OR}=0.48,95 \% \mathrm{CI}[0.38-0.60])$ and suicide attempts $(\mathrm{OR}=0.80,95 \% \mathrm{CI}$ [0.70-0.90]). Among believers, religious observance was not associated with psychotic outcomes.

\section{Conclusions}

Religiosity appears to be a complex and bidirectional determinant of psychiatric symptoms and disorders. In this respect, religiosity should be more thoroughly assessed in epidemiological psychiatric studies, as well as in clinical practice.

\section{Keywords}

Religious beliefs; Religious observance; Mood disorders; Suicide attempts; Psychotic disorders. 


\section{INTRODUCTION}

According to Emile Durkheim, religion provides rules of conduct for individuals and thus allows for social integration and regulation. His work, entitled «Le Suicide », published in 1897, was the first sociological study to examine the effect of religion on suicide risk [1]. Durkheim analyzed variations in suicide rates among different social groups in France, particularly religious groups, and found a protective effect of religion membership against suicide. Since then, a substantial amount of scientific studies have addressed the question of the protective effect of religion on suicidality. However, the results found were contradictory. For instance, in Ireland, religious affiliation was not associated with significant variations in the risk of death by suicide [2]; while in a representative sample of the general population of the United Kingdom, the prevalence of suicidal ideation and suicide attempts was significantly lower among religious groups, in comparison to non-religious groups [3]. In a 42-country study, Hsieh found significant variations in this association [4]. More precisely, religious involvement was associated with lower rates of death by suicide in Latin America, Eastern and Northern Europe, and English-speaking countries, but higher rates in East Asia, Western and Southern Europe. These results support the notion that the effect of religion on suicidality may not be the same in all regions of the world. Moreover, with regard to the relationship between suicide and religiosity, statistical adjustment on psychiatric disorders could bring significant insight. Finally, to our knowledge, no religiosity studies concerning suicide have focused on the French general population since Durkheim's work.

The effect of religious affiliation and participation on the rates of psychiatric disorders has also been studied. Regarding depression, several studies and meta analyses have found protective effects of religion [5-7]. Religion also appears to be protective against addictive disorders [8, 9]. Regarding anxiety disorders, studies have found non-significant differences, or slight associations between religion and lower rates of anxiety disorders $[10,11]$. Regarding psychotic disorders, the relationship between religion and prognosis and quality of life for patients has been extensively studied [12-14], and the prevalence of psychotic symptoms has been shown to be associated with religion [15]. However, to our knowledge, no studies have ever assessed the risk of psychotic disorders according to religious affiliation or participation. Overall, as for suicide outcomes, no studies about the relationship between religiosity and the prevalence of psychiatric disorders has been carried out in France, and it is of great importance to study these associations within a specific context, due to specific cultural aspects. Migration, which is associated with specific risks of psychiatric disorders [16-18], may also influence this association [19, 20], and, to our knowledge, no studies have adjusted for this risk factor. 
In this context, the objective of this study was to analyze the association between religious beliefs and practice and the prevalence of suicide attempts, psychiatric disorders, and psychotic symptoms in a large sample of the French general population while adjusting for several sociodemographic variables, including migration status. Our hypothesis is that religiosity remains negatively associated with suicide and is protective against most psychiatric disorders. 


\section{METHODS}

\section{Mental Health in the General Population (MHGP) survey}

This study is an explorative secondary analysis of MHGP survey. This survey was conducted by the World Health Organization-Collaborating Centre (WHO-CC) between 1999 and 2003, and interviewed 38,694 subjects at 47 study sites. Approximately 900 participants were selected using the quota sampling method from each site [21]. This method provides a sample of a population with similar characteristics to the overall population, i.e., age, sex, and level of education. The initial objective of this survey was to describe the perceptions and representations of mental health in the general population. The inclusion criteria were as follows: the subject providing consent, being 18 years old or above, being francophone, and not being hospitalized or homeless.

\section{Socio-demographic variables}

The following socio-demographic values were collected: age, sex, education level, marital status, income level and migration status (native, first, second or third generation migration).

\section{Religiosity}

For each participant, religiosity was assessed on the basis of religious beliefs and religious practice. These were identified by means of two questions: “are you a believer?" and "are you religiously observant?". Participants answered with "Yes" or with "No" to these two questions.

\section{Psychiatric disorders}

The Mini International Neuropsychiatric Interview (MINI, French version 5.0.0) was used to screen for major psychiatric disorders as defined by the 10th version of the International Classification of Diseases (ICD-10). It has excellent validity, reliability (inter-rater and test-retest), sensitivity and specificity [22, 23]. A three-day training course about MINI administration, organized by the WHO-CC, was given to the MHGP survey evaluators (i.e., nursing students and psychologists) [24]. The psychiatric disorders studied were: lifetime bipolar disorder (BD, F31), current unipolar depressive disorder (UDD, F32 and F33), current generalized anxiety disorder (GAD) (F41.1), current panic disorder (F41.0), current social anxiety disorder (SAD, F40.1), current post-traumatic stress disorder (PTSD) (F43.1), one-year alcohol use disorders (AUD) (F10) and one-year substance use disorders (SUD) (F19). Lifetime history of suicidal attempts was also assessed. With regard to psychotic disorders, 7 psychotic symptoms were assessed, including five items that assess the lifetime occurrence of delusional symptoms: delusions of persecution, thought broadcasting, delusions of control, delusions of reference, and other delusional ideas (e.g., somatic delusions or delusions of grandiosity); and two items that assess the lifetime occurrence of visual and auditory hallucinations. The 
diagnosis of a lifetime psychotic disorder was assessed by the presence of psychotic symptoms in the MINI and confirmed by a clinician who was familiar with transcultural psychiatry. Other details on the MHGP survey are available elsewhere [25-27].

\section{Statistical Analysis}

To study the association between religious status and psychiatric disorders, the prevalence of psychiatric disorders, psychotic symptoms, and suicide attempts were assessed according to religious beliefs and religious observance. To analyze the role of religious observance specifically and separately from beliefs, the analyses concerning religious observance were repeated among believers. The statistical analyses used were chi-square tests for bivariate analyses, and binomial logistic regressions for the multivariable analyses. Binomial logistic regressions were adjusted for the following factors: age, sex, education level, migration status, economic level and marital status. Concerning the history of suicide attempts, to exclude the influence of the different psychiatric disorders, analyses were repeated with additional adjustment for the different psychiatric disorders (i.e., mood, anxiety, addictive and psychotic). The statistical analyses were performed using R software [28]. 


\section{RESULTS}

\section{Religious beliefs and observance}

Of the 38,694 subjects interviewed in the SMPG survey, 21,634 (59.0\%) reported being religious believers, and 8,794 (22.7\%) reported being religiously observant. Subjects who were not believers were considered as non-observant. Among believers, 12,793 (59.1\%) were not observant. Among those who were religiously observant, $63(0.7 \%)$ were not believers (see Table 1 for the details).

\section{- TABLE 1 -}

\section{Sociodemographic variables}

Sociodemographic characteristics of the study population are detailed in Table 2. Age was associated with religiosity, with higher rates of religiosity among people aged over 60 years-old $(75.4 \%$ of beliefs in $60+$ age-band vs. $60.7 \%$ and less in the other age-bands, $41.1 \%$ of observance vs. $22.2 \%$ and less). Women were more religious than men (beliefs: $64.4 \%$ vs. $52.8 \%$, observance: $27.9 \%$ vs. $19.5 \%$ ). Subjects with lower levels of education and income were also more religious. Finally, first- and second-generation migrants were more religious than natives and third-generation migrants (beliefs: $76.2 \%$ and $66.2 \%$ for first- and secondgeneration vs. $57.6 \%$ and less for native and third-generation; observance: $43.6 \%$ and $28.0 \%$ vs. $23.2 \%$ and less).

\section{- TABLE 2 -}

\section{Religiosity and suicide}

Religious beliefs $(\mathrm{OR}=0.90,95 \%$ CI [0.82-0.99]) and, more importantly, religious observance $(\mathrm{OR}=0.79$, 95\% CI [0.70-0.89]) appeared to be associated with lower rates of history of suicide attempts. Contrary to the association with religious beliefs, the association with religious observance remained significant after Bonferroni correction. Additional analyses which were adjusted for other psychiatric disorders (i.e., mood, anxiety, addictive and psychotic disorders) found the same associations (beliefs: OR=0.88, 95\% CI [0.800.97], observance: $\mathrm{OR}=0.80,95 \% \mathrm{CI}[0.70-0.90])$.

\section{Religiosity and mood disorders}

Religious beliefs (OR=1.15, 95\% CI [1.06-1.23]) were associated with a higher UDD rate (and remained significant after Bonferroni correction), contrary to religious observance (OR=0.99, 95\% CI [0.91-1.08]) which was not significantly associated. 
Religious beliefs ( $\mathrm{OR}=0.83$, 95\% CI [0.69-0.98]) were associated with a lower rate of $\mathrm{BD}$, contrary to religious observance $(\mathrm{OR}=0.88$, 95\% CI [0.70-1.09]) which was not significantly associated. This association did not remain significant after Bonferroni correction.

\section{Religiosity and anxiety disorders}

Religious beliefs (OR=1.13, 95\% CI [1.06-1.21]) were associated with a higher rate of GAD (and remained significant after Bonferroni correction), but not religious observance (OR=0.98, 95\% CI [0.90-1.06]).

Religious beliefs (OR=1.06, 95\% CI [0.96-1.18]) were not associated with SAD rate, contrary to religious observance $(\mathrm{OR}=0.87,95 \% \mathrm{CI}$ [0.76-0.99]) which was significantly associated with a lower rate. This association did not remain significant after Bonferroni correction.

Religious beliefs and observance were not associated with panic disorder and PTSD rates (beliefs: OR=1.09, 95\% CI [0.99-1.20] for panic disorder, and OR=0.90, 95\% CI [0.69-1.18] for PTSD; observance: OR=1.00, 95\% CI [0.89-1.11] for panic disorder, OR=1.10, 95\% CI [0.81-1.47] for PTSD).

\section{Religiosity and addictive disorders}

AUD and SUD were less frequent among subjects with religious beliefs (OR=0.69, 95\% CI [0.69-0.77] for AUD; OR=0.60, 95\% CI [0.52-0.69] for SUD), and with religious observance (OR=0.60, 95\% CI [0.510.70] for AUD; OR=0.48, 95\% CI [0.38-0.60] for SUD). Theses associations did not remain significant after Bonferroni correction.

\section{Religiosity and psychosis}

Psychotic symptoms were more frequent among subjects with religious beliefs $(\mathrm{OR}=1.37$, 95\% CI [1.301.45]) and with observance ( $\mathrm{OR}=1.14,95 \%$ CI [1.08-1.21]). Regarding psychotic disorders, the associations were the same (beliefs: $\mathrm{OR}=1.38$, 95\% CI [1.20-1.58], and observance: OR=1.25, 95\% CI [1.07-1.45]). Except for psychotic disorders and religious observance, theses associations did not remain significant after Bonferroni correction.

Details of prevalence and bivariate and multivariable comparisons according to religiosity are available in Tables 3 and 4 .

\section{- TABLES 3 AND 4 -}

\section{Analyses of religious observance among believers}

Religious observance among believers was associated with the same effect as in the total sample for the following outcomes: history of suicide attempts (OR=0.83, 95\% CI [0.72-0.94]), SAD (OR=0.81, 95\% CI 
[0.70-0.94]), AUD (OR=0.70, 95\% CI [0.58-0.83]), and SUD (OR=0.60, 95\% CI [0.46-0.77]). The associations with the addictive disorders remained significant after Bonferroni correction. As in the total sample, religious observance was not associated with UDD (OR=0.92, 95\% CI [0.84-1.00]), BD (OR=0.98, 95\% CI [0.76-1.27]), panic disorder (OR=0.95, 95\% CI [0.84-1.07]) or PTSD (OR=1.18, 95\% CI [0.841.66]). In contrast to the total sample, psychotic disorders $(\mathrm{OR}=1.09,95 \% \mathrm{CI}$ [0.92-1.28]) and symptoms $(\mathrm{OR}=0.98,95 \% \mathrm{CI}[0.91-1.28])$ were not associated with religious observance; and GAD (OR=0.90, 95\% CI [0.82-0.98]) was slightly negatively associated with religious observance. See details of prevalence in Table 5.

- TABLE 5 - 


\section{DISCUSSION}

Our study analyzed the association between the prevalence of suicide attempts, psychiatric disorders and psychotic symptoms, and religious beliefs and observance. The analyses were adjusted for migrant status, among other factors. Interestingly, religious beliefs and observance had different relationships with psychiatric disorders. Indeed, a positive association was found with psychotic disorders, UDD and GAD. Conversely, a negative association was found between religiosity and history of suicide attempts, BD, SAD, and, to a greater degree, with addictive disorders. Moreover, religious observance had almost the same relationships with the outcomes when analyzed in the total sample and specifically among believers.

The relationships between religiosity and psychiatric outcomes are analyzed cross-sectionally in the present study. The major bias of such studies is the lack of information concerning whether religious characteristics were present in subjects before the onset of psychiatric disorders. Indeed, religiosity for subjects with psychiatric disorders could be considered as coping strategies (e.g., relief for psychological distress) and thus occur after the onset of psychiatric disorders. Thus, religiosity as either a protective or risk factor to psychiatric outcomes can only be hypothesized. However, some of the associations observed in this study have been found in longitudinal studies (see below); and both religious beliefs and observance may have psychopathological effects. On the one hand, the belief in God or any other spiritual belief should provide relief (and thus prevent psychiatric disorders) in addressing life adversities [29, 30]. Moreover, concerning observance, the religious community may bring social support to the observant individual which could be protective against loneliness, also a major risk factor for psychiatric disorders [31-33]. This social role of religiosity could also provide potential support for subjects with psychiatric patients, and thus prevent clinical worsening and encourage recovery [34]. On the other hand, religious beliefs may increase the feeling of responsibility, and thus the feeling of guilt; and religious observance is codified by rules that could be difficult to comply with. Furthermore, religiosity may increase proneness to delusional ideas and hallucinatory perceptions [35]. Some authors describe religious beliefs as falling within a spectrum of belief from the norm to delusion [36]. According to Pierre, a dimensional approach to delusion would be more relevant in differentiating the normal from the pathological, rather than assessing the context of the religious belief itself [37]. The different associations found in our study may be discussed in light of these different issues. Furthermore, comparisons with studies across countries are difficult. For instance, American studies may be influenced by the weight of religion in American society which is different from the weight of religion in French society [38]. France is characterized by secular customs, and the place of religion belongs primarily to the private sphere. Thus, the impact of religion on socio-cultural codes is uneven compared to other less secularized societies. 
The negative association between religiosity and suicide is consistent with Durkheim's work. Since then, several cross-sectional European studies have also studied this association. Using similar methodology in a representative sample of the general population of the United Kingdom, Jacob et al. found consistently lower prevalence of suicidal ideation and attempts among subjects with a religion (whole suicidality lifetime: $\mathrm{OR}=0.83,95 \% \mathrm{CI}$ [0.69-0.99]) [3]. The major strength of our study is to provide supplementary and consistent analysis of this association adjusted for the different psychiatric disorders. Thus, the statistical association of religiosity is the same after adjustment for psychiatric disorders, which is consistent with a negative association against suicide, even among patients with psychiatric disorders [10]. As the survey was cross-sectional, no causal conclusions can be stated. However, prospective studies in the USA and a systematic review of 17 worldwide studies confirmed our cross-sectional findings [39-41]. Moreover, a study based on 162 European regions found a "dose-effect" negative relationship between suicide rate and the strength of subjective religiosity [42]. These negative associations may be explained by the moral judgment of suicide induced by religion. Indeed, suicide is explicitly forbidden in monotheistic religions such as Judaism, Christianity, and Islam [3]. However, Durkheim stated that the negative association found is not linked to any religious condemnation of suicide but rather to the influence of the society formed by the sharing of common beliefs and practices [1]. Comparing the suicide rates in different religious groups, he argued that the stronger the ties of the community were, the more protective the community was against suicide. The dogma of communication with a divine being or the immortality of the soul would therefore be secondary.

The negative association of religiosity with addictive disorders suggested a protective effect, which was stronger than that for suicide attempts, could also be related to religious doctrines against taking and/or abusing alcohol and/or drugs. The negative association found in our results is consistent with previous studies on this topic [9, 43-45]. Of note, among all psychiatric disorders, the negative association of religiosity appeared to be the strongest for addictive disorders. Edlund et al. have analyzed the role of mental health status and social support in this negative association, and found significant but small associations [46]. Other studies found an association linking factors relating to religiosity as a whole: social religiosity, fear of God's judgment, forgiveness, and/or thankfulness [9, 47].

However, owing to the fact that depressive symptoms are strong predictive factors of suicidality across psychiatric disorders [48-51] and that negative associations have been found in most studies, the positive association of religious beliefs with UDD is surprising. In an international and prospective study, Leurent et al. found a higher prevalence of depression among religious compared to non-religious subjects [52]. An explanation of these conflicting results could be that findings in any specific population may not generalize to another. Furthermore, the association of the present study between depression and religious beliefs was weak, whereas religious observance was not associated with UDD in the total sample nor in the believer 
sample. Regarding BD, little evidence is found in previous studies. A clinical review based on 5 studies that used homogeneous samples of BD patients did not find significant differences [53]. Contrary to the results of our study, some authors suggested that a higher incidence of strong religious experiences was described in mania [54], as if religious activity could have an influence in hypomanic/manic phases for BD patients. However, and also surprisingly regarding the positive association with UDD, our study found a slight negative association between $\mathrm{BD}$ and religious beliefs, and an absence of association with religious observance.

Regarding anxiety disorders, a mild positive association between religious beliefs and GAD was found in our study, whereas, surprisingly, a negative association with religious observance was found among believers, enhancing the fact that beliefs and observance may have different psychiatric consequences. SAD was also negatively associated with the observance in the total sample and among believers, without association with beliefs. In comparison to suicide, depression or addictive disorders, fewer studies analyzed the association between anxiety disorders and religion. These studies were in favor of a protective effect of religiosity on anxiety disorders rates. In a literature review in 2014, Khalaf et al. found 10 studies addressing the rates of anxiety disorders according to religiosity [11]. Concerning GAD, studies found conflicting results ( 4 studies found a protective effect of religiosity, and 2 found an association between religiosity and GAD). The studies on SAD found insignificant associations. In a longitudinal study, Rasic et al. have followed more than 1000 subjects over a period of more than 10 years and did not find any association between any anxiety disorders and religiosity or spirituality [10].

The results of our study concerning psychotic outcomes (association with beliefs and observance in the total sample, but no association with observance among believers) are in favor of a stronger association with religious beliefs rather than religious observance. To our knowledge, no studies to date have assessed the risk of psychotic disorders according to religious characteristics. Concerning psychotic symptoms, the results of previous studies were also conflicting. Several studies have looked at multiple ethnic groups and found variations in the association between religiosity and psychotic symptoms $[15,55]$. In Kovess-Masfety et al. World Health organization study across 18 countries, including France, no associations were found between religious affiliation and psychotic symptoms [56]. Focusing on specific subgroups in the same study, such as individuals with high religious investment, authors revealed higher rates of psychotic symptoms. Moreover, a Loch and al. study focused on the impact of organizational religious activity and perceptual abnormalities/hallucinations in individuals at ultra-high risk for psychosis and found a positive association [57]. The authors hypothesized that churches and religious organizations could be used to cope with hallucinations. Furthermore, such associations raise the question about the boundaries between religious beliefs and delusional symptoms [58]. Mystical themes are recurrent in delusions, e.g., megalomania and persecutory ideas that contain elements related to God or the devil. In addition, 
hallucinatory experiences could be integrated into a spiritual dimension, e.g., in communicative experiences with God. Furthermore, in our study, religiosity appeared negatively associated with suicide, and positively with psychotic symptoms. The link between suicide and psychotic symptoms has been extensively shown, including in MHGP survey $[59,60]$. Several clusters of psychotic symptoms could exist, with symptoms related to religiosity, and other to psychopathology. Further studies are necessary to disentangle the links between suicide, psychotic symptoms and religiosity.

A large number of participants were drawn from the general population, instead of subgroups, which provided a strong statistical base. Moreover, this is the first study conducted on the subject in the French population to our knowledge. However, the survey was conducted in the early 2000s, and thus the results need to be interpreted with caution, as religiosity is decreasing in the French society [61]. Furthermore, some limitations of the study should be mentioned. First of all, the large-scale questionnaires involved retrospective data collection, as well as refusals to participate. Some refusals could be explained by the private and intimate nature of religiosity to certain people. Moreover, the quota method was used to select the subjects, and not a probabilistic one, which could affect the representativeness of the sample population. Finally, the exclusion of homeless and institutionalized individuals induced a bias due to the high prevalence of psychiatric disorders in these populations. The multiple definitions of the criteria "religiosity" should also be highlighted $[9,10,47,52]$. The strengths of participants' faith, the attendance at places of worship, the number of prayers, the belief in life after death or the belief in a supernatural force are religious criteria that would also have been interesting to study but were unavailable in MHGP survey. Therefore, religious beliefs and observance were assessed binarily, without assessment of the degree of religiosity or the timeframe of putative religiosity. Because of the cross-sectional nature of the study, no causal link can be determined. In addition, this study is prevalence-based, and thus could be influenced not only by religiosity, but also by different courses of the disease according to these risk factors. As discussed above, a possible bias is that religiosity could be secondary to the psychiatric disorder.

The present study shows positive and negative associations between religiosity and psychiatric disorders. The paradox of both negative associations with suicide and positive associations with UDD needs to be addressed, e.g., studying the prognosis role of religiosity among patients with depression or other psychiatric disorders. Likewise, the association with psychotic symptoms, which are present in several psychiatric disorders, could be considered paradoxical as religiosity is negatively associated with some of these disorders (bipolar or addictive disorders). Finally, as it can be crucial for our patients, religious beliefs and observance should be considered when taking preliminary case histories. More studies are needed to shed light on the mechanisms of the association between religiosity as a clinical factor in psychiatry. 


\section{Acknowledgements:}

None.

\section{Financial support:}

This research received no specific grant from any funding agency, commercial or not-for-profit sectors.

\section{Conflict of Interest:}

None.

\section{Ethical Standards:}

The authors assert that all procedures contributing to this work comply with the ethical standards of the relevant national and institutional committees on human experimentation and with the Helsinki Declaration of 1975 , as revised in 2008.

Legal authorization was obtained by the "Commission Nationale Informatique et Liberté" (CNIL) and the "Comité consultatif sur le traitement de l'information en matière de recherche" (CCTIRS), with number 98.126.

\section{Availability of Data and Materials:}

The data is not available in open access. 


\section{REFERENCES}

1. Durkheim E (2002) Le Suicide. J.-M. Tremblay, Chicoutimi

2. O'Reilly D, Rosato M (2015) Religion and the risk of suicide: longitudinal study of over 1 million people. Br J Psychiatry 206:466-470. https://doi.org/10.1192/bjp.bp.113.128694

3. Jacob L, Haro JM, Koyanagi A (2019) The association of religiosity with suicidal ideation and suicide attempts in the United Kingdom. Acta Psychiatr Scand 139:164-173. https://doi.org/10.1111/acps.12972

4. Hsieh N (2017) A Global Perspective on Religious Participation and Suicide. J Health Soc Behav 58:322-339. https://doi.org/10.1177/0022146517715896

5. Braam AW, Van Den Eeden P, Prince MJ, et al (2001) Religion as a cross-cultural determinant of depression in elderly Europeans: results from the EURODEP collaboration. Psychol Med 31:803814. https://doi.org/10.1017/S0033291701003956

6. Smith TB, McCullough ME, Poll J (2003) Religiousness and depression: Evidence for a main effect and the moderating influence of stressful life events. Psychol Bull 129:614-636. https://doi.org/10.1037/0033-2909.129.4.614

7. Miller L, Wickramaratne P, Gameroff MJ, et al (2012) Religiosity and Major Depression in Adults at High Risk: A Ten-Year Prospective Study. Am J Psychiatry 169:89-94. https://doi.org/10.1176/appi.ajp.2011.10121823

8. Miller L, Davies M, Greenwald S (2000) Religiosity and Substance Use and Abuse Among Adolescents in the National Comorbidity Survey. J Am Acad Child Adolesc Psychiatry 39:1190-1197. https://doi.org/10.1097/00004583-200009000-00020

9. Vance T, Maes HH, Kendler KS (2014) A Multivariate Twin Study of the Dimensions of Religiosity and Common Psychiatric and Substance Use Disorders: J Nerv Ment Dis 202:360-367. https://doi.org/10.1097/NMD.0000000000000131

10. Rasic D, Robinson JA, Bolton J, et al (2011) Longitudinal relationships of religious worship attendance and spirituality with major depression, anxiety disorders, and suicidal ideation and attempts: Findings from the Baltimore epidemiologic catchment area study. J Psychiatr Res 45:848-854. https://doi.org/10.1016/j.jpsychires.2010.11.014 
11. Khalaf DR, Hebborn LF, Dal SJ, Naja WJ (2015) A Critical Comprehensive Review of Religiosity and Anxiety Disorders in Adults. J Relig Health 54:1438-1450. https://doi.org/10.1007/s10943-0149981-5

12. Bonelli RM, Koenig HG (2013) Mental Disorders, Religion and Spirituality 1990 to 2010: A Systematic Evidence-Based Review. J Relig Health 52:657-673. https://doi.org/10.1007/s10943-013-9691-4

13. Borras L, Mohr S, Brandt P-Y, et al (2007) Religious Beliefs in Schizophrenia: Their Relevance for Adherence to Treatment. Schizophr Bull 33:1238-1246. https://doi.org/10.1093/schbul/sbl070

14. Caqueo-Urízar A, Urzúa A, Boyer L, Williams DR (2016) Religion involvement and quality of life in patients with schizophrenia in Latin America. Soc Psychiatry Psychiatr Epidemiol 51:521-528. https://doi.org/10.1007/s00127-015-1156-5

15. Oh H, Waldman K, Koyanagi A (2018) Psychotic experiences and religiosity: Findings from the collaborative psychiatric epidemiological surveys. Schizophr Res 201:435-436. https://doi.org/10.1016/j.schres.2018.05.037

16. Amad A, Guardia D, Salleron J, et al (2013) Increased prevalence of psychotic disorders among thirdgeneration migrants: Results from the French Mental Health in General Population survey. Schizophr Res 147:193-195. https://doi.org/10.1016/j.schres.2013.03.011

17. Mindlis I, Boffetta P (2017) Mood disorders in first- and second-generation immigrants: Systematic review and meta-analysis. Br J Psychiatry 210:182-189. https://doi.org/10.1192/bjp.bp.116.181107

18. Selten J-P, van der Ven E, Termorshuizen F (2020) Migration and psychosis: a meta-analysis of incidence studies. Psychol Med 50:303-313. https://doi.org/10.1017/S0033291719000035

19. Johns LC, Cannon M, Singleton N, et al (2004) Prevalence and correlates of self-reported psychotic symptoms in the British population. $\mathrm{Br} \mathrm{J}$ Psychiatry 185:298-305. https://doi.org/10.1192/bjp.185.4.298

20. Jordanova V, Crawford MJ, McManus S, et al (2015) Religious discrimination and common mental disorders in England: a nationally representative population-based study. Soc Psychiatry Psychiatr Epidemiol 50:1723-1729. https://doi.org/10.1007/s00127-015-1110-6

21. Lunsford TR, Lunsford BR (1995) The Research Sample, Part I: Sampling. JPO J Prosthet Orthot 7:

22. Lecrubier Y, Sheehan D, Weiller E, et al (1997) The Mini International Neuropsychiatric Interview (MINI). A short diagnostic structured interview: reliability and validity according to the CIDI. Eur Psychiatry 12:224-231. https://doi.org/10.1016/S0924-9338(97)83296-8 
23. Sheehan DV, Lecrubier Y, Sheehan KH, et al (1998) The Mini-International Neuropsychiatric Interview (M.I.N.I.): the development and validation of a structured diagnostic psychiatric interview for DSMIV and ICD-10. J Clin Psychiatry 59 Suppl 20:22-33;quiz 34-57

24. Caria A, Roelandt J-L, Bellamy V, Vandeborre A (2010) «Santé Mentale en Population Générale : Images et Réalités (Smpg)»: Présentation de La méthodologie d'enquête. L'Encéphale 36:1-6. https://doi.org/10.1016/S0013-7006(10)70011-7

25. Pignon B, Geoffroy PA, Thomas P, et al (2017) Prevalence and clinical severity of mood disorders among first-, second- and third-generation migrants. J Affect Disord 210:174-180. https://doi.org/10.1016/j.jad.2016.12.039

26. Pignon B, Amad A, Pelissolo A, et al (2018) Increased prevalence of anxiety disorders in thirdgeneration migrants in comparison to natives and to first-generation migrants. J Psychiatr Res 102:38-43. https://doi.org/10.1016/j.jpsychires.2018.03.007

27. Pignon B, Peyre H, Szöke A, et al (2018) A latent class analysis of psychotic symptoms in the general population. Aust N Z J Psychiatry 52:573-584. https://doi.org/10.1177/0004867417744255

28. R Core Team R: A language and environment for statistical computing. R Foundation for Statistical Computing, version 3.3.0 [Internet]. Vienna, Austria; 2013. Available from: http://www.Rproject.org

29. Korkeila J, Vahtera J, Nabi H, et al (2010) Childhood adversities, adulthood life events and depression. J Affect Disord 127:130-138

30. Beards S, Gayer-Anderson C, Borges S, et al (2013) Life events and psychosis: a review and metaanalysis. Schizophr Bull 39:740-747

31. Beutel ME, Klein EM, Brähler E, et al (2017) Loneliness in the general population: prevalence, determinants and relations to mental health. BMC Psychiatry 17:97

32. Erzen E, Çikrikci Ö (2018) The effect of loneliness on depression: A meta-analysis. Int J Soc Psychiatry $64: 427-435$

33. Michalska da Rocha B, Rhodes S, Vasilopoulou E, Hutton P (2018) Loneliness in Psychosis: A Metaanalytical Review. Schizophr Bull 44:114-125

34. Shahid M, Raza SS (2018) Religion/Spirituality: A Tool to Better Help Psychiatric Patients. J Coll Physicians Surg--Pak JCPSP 28:578. https://doi.org/10.29271/jcpsp.2018.07.578 
35. Steenhuis LA, Bartels-Velthuis AA, Jenner JA, et al (2016) Religiosity in young adolescents with auditory vocal hallucinations. Psychiatry Res 236:158-164. https://doi.org/10.1016/j.psychres.2015.12.014

36. Abdel Gawad N, Desai P, Ali T, et al (2018) Religious Activity, Psychotic Features, and Suicidality in 688 Acute Psychiatric Inpatients: J Psychiatr Pract 24:253-260. https://doi.org/10.1097/PRA.0000000000000311

37. Pierre JM (2001) Faith or Delusion? At the Crossroads of Religion and Psychosis: J Psychiatr Pract 7:163-172. https://doi.org/10.1097/00131746-200105000-00004

38. Debray R. (2004) God: An Itinerary. London; New York: Verso, p 312p

39. Kleiman EM, Liu RT (2014) Prospective prediction of suicide in a nationally representative sample: religious service attendance as a protective factor. $\mathrm{Br} \mathrm{J}$ Psychiatry 204:262-266. https://doi.org/10.1192/bjp.bp.113.128900

40. VanderWeele TJ, Li S, Tsai AC, Kawachi I (2016) Association Between Religious Service Attendance and Lower Suicide Rates Among US Women. JAMA Psychiatry 73:845. https://doi.org/10.1001/jamapsychiatry.2016.1243

41. Lawrence RE, Oquendo MA, Stanley B (2016) Religion and Suicide Risk: A Systematic Review. Arch Suicide Res 20:1-21. https://doi.org/10.1080/13811118.2015.1004494

42. Stack S, Laubepin F (2019) Religiousness as a Predictor of Suicide: An Analysis of 162 European Regions. Suicide Life Threat Behav 49:371-381. https://doi.org/10.1111/sltb.12435

43. Heinz A, Epstein DH, Preston KL (2007) Spiritual/Religious Experiences and In-Treatment Outcome in an Inner-City Program for Heroin and Cocaine Dependence. J Psychoactive Drugs 39:41-49. https://doi.org/10.1080/02791072.2007.10399863

44. Dew RE, Daniel SS, Armstrong TD, et al (2008) Religion/Spirituality and Adolescent Psychiatric Symptoms: A Review. Child Psychiatry Hum Dev 39:381-398. https://doi.org/10.1007/s10578-0070093-2

45. Tuck A, Robinson M, Agic B, et al (2017) Religion, Alcohol Use and Risk Drinking Among Canadian Adults Living in Ontario. J Relig Health 56:2023-2038. https://doi.org/10.1007/s10943-016-0339-z

46. Edlund MJ, Harris KM, Koenig HG, et al (2010) Religiosity and decreased risk of substance use disorders: is the effect mediated by social support or mental health status? Soc Psychiatry Psychiatr Epidemiol 45:827-836 
47. Kendler KS, Liu X-Q, Gardner CO, et al (2003) Dimensions of religiosity and their relationship to lifetime psychiatric and substance use disorders. Am J Psychiatry 160:496-503

48. Cavanagh JTO, Carson AJ, Sharpe M, Lawrie SM (2003) Psychological autopsy studies of suicide: a systematic review. Psychol Med 33:395-405

49. Arsenault-Lapierre G, Kim C, Turecki G (2004) Psychiatric diagnoses in 3275 suicides: a meta-analysis. BMC Psychiatry 4:37

50. Roux P, Misdrahi D, Capdevielle D, et al (2018) Mediation Analyses of Insight, Quality of Life, Depression, and Suicidality: Results From the FACE-SZ Cohort. J Clin Psychiatry 79:pii: 17m11638

51. Miller JN, Black DW (2020) Bipolar Disorder and Suicide: a Review. Curr Psychiatry Rep 22:6. https://doi.org/10.1007/s11920-020-1130-0

52. Leurent B, Nazareth I, Bellón-Saameño J, et al (2013) Spiritual and religious beliefs as risk factors for the onset of major depression: an international cohort study. Psychol Med 43:2109-2120. https://doi.org/10.1017/S0033291712003066

53. De Fazio P, Gaetano R, Caroleo M, et al (2015) Religiousness and spirituality in patients with bipolar disorder. Int J Psychiatry Clin Pract 19:233-237. https://doi.org/10.3109/13651501.2014.1000929

54. Gallemore JL, Wilson WP, Rhoads JM (1969) The religious life of patients with affective disorders. Dis Nerv Syst 30:483-487

55. Earl TR, Fortuna LR, Gao S, et al (2015) An exploration of how psychotic-like symptoms are experienced, endorsed, and understood from the National Latino and Asian American Study and National Survey of American Life. Ethn Health 20:273-292. https://doi.org/10.1080/13557858.2014.921888

56. Kovess-Masfety V, Saha S, Lim CCW, et al (2018) Psychotic experiences and religiosity: data from the WHO World Mental Health Surveys. Acta Psychiatr Scand 137:306-315. https://doi.org/10.1111/acps.12859

57. Loch AA, Freitas EL, Hortêncio L, et al (2019) Hearing spirits? Religiosity in individuals at risk for psychosis-Results from the Brazilian SSAPP cohort. Schizophr Res 204:353-359. https://doi.org/10.1016/j.schres.2018.09.020

58. Ventriglio A, Bonfitto I, Ricci F, et al (2018) Delusion, possession and religion. Nord J Psychiatry 72:S13-S15 
59. DeVylder JE, Lukens EP, Link BG, Lieberman JA (2015) Suicidal Ideation and Suicide Attempts Among Adults With Psychotic Experiences: Data From the Collaborative Psychiatric Epidemiology Surveys. JAMA Psychiatry 72:219. https://doi.org/10.1001/jamapsychiatry.2014.2663

60. Pignon B, Schürhoff F, Szöke A, et al (2018) Sociodemographic and clinical correlates of psychotic symptoms in the general population: Findings from the MHGP survey. Schizophr Res 193:336-342. https://doi.org/10.1016/j.schres.2017.06.053

61. Todd E (2019) Lineages of Modernity: A History of Humanity from the Stone Age to Homo Americanus. Polity Press, Cambridge : Medford, MA 